\title{
The 28-day survive for critically ill cancer patients undergoing continuous renal replacement with postoperative acute kidney injure: a retrospective study of 86 cases
}

\author{
Zhen-Nan Yuan, Hai-Jun Wang, Shi-Ning Qu, Chu-Lin Huang, Hao Wang, Hao Zhang, \\ Quan-Hui Yang, Xue-Zhong Xing \\ Department of Intensive Care Unit, National Cancer Center/National Clinical Research Center for Cancer/Cancer Hospital, Chinese Academy of \\ Medical Sciences \& Peking Union Medical College, Beijing, China \\ Contributions: (I) Conception and design: XZ Xing, ZN Yuan; (II) Administrative support: XZ Xing; (III) Provision of study materials or patients: SN \\ Qu, CL Huang, H Wang; (IV) Collection and assembly of data: H Zhang, ZN Yuan; (V) Data analysis and interpretation: QH Yang, ZN Yuan; (VI) \\ Manuscript writing: All authors; (VII) Final approval of manuscript: All authors. \\ Correspondence to: Xue-Zhong Xing. Department of Intensive Care Unit, National Cancer Center/National Clinical Research Center for Cancer/ \\ Cancer Hospital, Chinese Academy of Medical Sciences \& Peking Union Medical College, Beijing, China. Email: xingxuezhong@cicams.ac.cn.
}

Background: Advances in oncology led to a substantial increase in the number of patients requiring admission to the intensive care unit (ICU). It remains controversial to start continuous renal replacement therapy (CRRT) for acute kidney injure (AKI) in critically ill patients with cancer because of the poor outcome and high costs.

Methods: In this retrospective study, we collected data from patients with cancer with postoperative AKIstage 3 [Kidney Disease: Improving Global Outcomes (KDIGO), 2012] undergoing CRRT in the ICU of Cancer Hospital, Chinese Academy of Medical Sciences from January 2010 to January 2019. Patients were followed up until the time of death or the point of 28-day after ICU admission. Univariate and multivariate analysis was performed to identify risk factors for 28-day survive.

Results: Of 8,030 cancer patients after surgical operation admitted by ICU, a total of 86 (1.1\%) patients developed postoperative AKI: male/female: 62/24, median age 61 [27-82] years. The number of digestive tract/lung/other types of cancer was 59, 10 and 17, respectively. The median Simplified Acute Physiology Score III (SAPS III) was 65 [49-109] and the median Sequential Organ Failure Assessment (SOFA) score was 6 [1-19]. There were 35 deaths eventually and all the deaths occur within 28 days after ICU admission. Twenty-eight-day survive rate was $57.1 \% \pm 5.8 \%$. In multivariate cox regression analysis, two risk factors independently affected 28-day survive: SAPS III score $\geq 65$ [hazard ratio (HR): 3.451 (1.272-9.365), P=0.015], the presence of shock at the start of CRRT [HR: 10.262 (2.210-47.660), $\mathrm{P}=0.003$ ]. The cancer status $(\mathrm{P}=0.076)$, cancer types $(\mathrm{P}>0.05$ for both) and neoadjuvant therapy associated with cancer $(\mathrm{P}=0.949)$ showed no effects on 28-day survive.

Conclusions: For cancer patients, postoperative AKI-stage 3 is a serious complication with a low 28-day survive rate. Patients with the presence shock at the start of CRRT or SAPS III $\geq 65$ will have a poor 28-day survive. It should be emphasized that the cancer characteristics (status, types or treatment) don't affect 28-day survive.

Keywords: Cancer; postoperative; acute kidney injure (AKI); survive; continuous renal replacement therapy (CRRT)

Submitted Mar 03, 2020. Accepted for publication Sep 14, 2020.

doi: $10.21037 /$ tcr-20-1324

View this article at: http://dx.doi.org/10.21037/tcr-20-1324 


\section{Introduction}

About 50\% cancer patients develop acute kidney injure (AKI) and most of them require renal replacement therapy (RRT) in the intensive care unit (ICU) $(1,2)$. AKI in these patients usually resulted from cancer itself (acute tumor lysis syndrome, urinary tract obstruction) and anticancer treatments (drug-induced nephropathy, major surgical procedures associated severe clinical complications such as ischemia, sepsis) (1-4). More and more cancer patients have opportunities to choose surgical therapy with the improvement of surgical techniques and neoadjuvant therapy (such as chemotherapy, radiotherapy before operation). Previous literature demonstrated the incidence of postoperative AKI varies from $1.1 \%$ to $17 \%$ (5-7), depending on the type of surgery. Postoperative AKI (especially in need of RRT) is a major cause of shortterm mortality among surgical patients (8). There is few literature on the prognosis for critically ill cancer patients undergoing continuous renal replacement therapy (CRRT) with no-cardiac postoperative AKI (1,9-11).

Historically, the presence of malignant disease had been a common reason for refusal of admission to ICU because of poor prognosis and high costs, especially those cancer patients with organ failure. We performed this study to investigate the 28-day survive of critically ill cancer patients undergoing CRRT with postoperative AKI, which may help make cancer-related prognosis judgments and make corresponding clinical decisions. We present the following article in accordance with the STROBE reporting checklist (available at http://dx. doi. org/10. 21037/tcr-20-1324).

\section{Methods}

\section{Setting and patients}

This retrospective study was conducted in the ICU of Cancer Hospital, Chinese Academy of Medical Sciences from January 2010 to January 2019. The ICU is a 12-bed unit (mainly to treat critical ill cancer patients after surgery). The study was conducted in accordance with the Declaration of Helsinki (as revised in 2013). The ethics committees in our hospital approved the study (No. NCC2020C-162) and the need for informed consent was waived because there was no interference with decisions related to patient's care.

Clinical data were retrospectively retrieved from patients' charts: gender, age, type of cancer, cancer status, cancer therapy, reasons for ICU admission, systolic blood pressure, the duration and the site of surgical operation, the presence of respiratory failure and/or shock at the time of the initiation of CRRT, the number of organ failures (including renal failure), the variables needed for calculating Sequential Organ Failure Assessment (SOFA) score and Simplified Acute Physiology Score III (SAPS III) in the first 24 hours after ICU admission. Global severity was assessed by SAPS III and SOFA. Laboratory data were collected at the start of CRRT from the medical records: serum albumin (ALB), creatinine (CRE), urea, procalcitonin (PCT), brain natriuretic peptide (BNP), troponin $\mathrm{T}(\mathrm{Tn} \mathrm{T})$, hemoglobin (HGB), white blood cell (WBC), platelets (PLT) (Table 1).

\section{Definition and decision for CRRT}

These patients were proved malignant neoplasm pathologically. All patients enrolled were classified as stage 3 [Kidney Disease: Improving Global Outcomes (KDIGO)] (increase in serum CRE by 3.0 times baseline; or increase in serum CRE to $353.6 \mathrm{~mol} / \mathrm{L}$; or urine output $<0.3 \mathrm{~mL} / \mathrm{kg} / \mathrm{h}$ for $\geq 24$ hours; or anuria for $\geq 12$ hours) according to 2012 KDIGO before the start of CRRT (12). Shock was defined as systolic blood pressure $<90$ or $40 \mathrm{mmHg}$ lower than basic blood pressure for more than 1 hour in need of vasoactive drugs. Respiratory failure was defined as $\mathrm{PaO}_{2} / \mathrm{FiO}_{2}$ ratio $<300 \mathrm{mmHg}$ or they were in need of mechanical ventilation (MV). SOFA score was based on six different scores, one each for the respiratory, cardiovascular, hepatic, coagulation, renal and neurological systems, extent of a patient's organ function as one to four (13). SAPS III was calculated based on guidelines provided by the SAPS III outcomes research group. Scores are generated using variables separated into three categories, all of which are available at time of admission (14).

Decision for CRRT was based on one (or more) of the following characteristics: uremia $>33.2 \mathrm{mmol} / \mathrm{L}$, hyperkalemia $>6.5 \mathrm{mmol} / \mathrm{L}$, severe metabolic acidosis $(\mathrm{pH}$ $<7.20$ ), clinical features of water overload, oliguria (urine output $<0.3 \mathrm{mg} / \mathrm{kg} / \mathrm{h}$ for $\geq 24$ hours) after completely fluid resuscitation.

\section{CRRT operation}

The CRRT modality was continuous venovenous hemofiltration $(\mathrm{CVVH})$ performed in a FAD100 machine (Braun, Rio de Janeiro, Brazil) using PAN-650SF membranes (Asahi Medical, Tokyo, Japan). Femoral or 
Table 1 Characteristics of 85 enrolled patients with cancer with AKI requiring CRRT

\begin{tabular}{|c|c|}
\hline Characteristics & $\mathrm{N}$ \\
\hline Sex (male/female) & $62 / 24$ \\
\hline Age, median [range] & 61 [27-82] \\
\hline \multicolumn{2}{|l|}{ Types of tumor (locoregional/metastatic) } \\
\hline Digestive tract & 59 \\
\hline Lung & 10 \\
\hline Others & 17 \\
\hline \multicolumn{2}{|l|}{ Cancer status } \\
\hline Locoregional & 67 \\
\hline Metastatic & 19 \\
\hline \multicolumn{2}{|l|}{$\begin{array}{l}\text { Neoadjuvant treatment given before ICU } \\
\text { admission }\end{array}$} \\
\hline Chemotherapy & 19 \\
\hline Radiotherapy & 3 \\
\hline \multicolumn{2}{|l|}{ Causes of ICU admission } \\
\hline Respiratory failure & 16 \\
\hline Shock & 23 \\
\hline Acute renal dysfunction & 47 \\
\hline \multicolumn{2}{|l|}{ Complications } \\
\hline Diabetes & 16 \\
\hline Hypertension & 35 \\
\hline Coronary heart disease & 12 \\
\hline Respiratory failure at start of CRRT & 53 \\
\hline Shock at start of CRRT & 49 \\
\hline Sepsis shock & 40 \\
\hline Ischemia shock & 9 \\
\hline SAPS III at ICU admission, median [range] & 65 [49-109] \\
\hline $\begin{array}{l}\text { SOFA score at ICU admission, median } \\
\text { [range] }\end{array}$ & $6[1-19]$ \\
\hline \multicolumn{2}{|l|}{ Number of organ failure at ICU admission } \\
\hline One organ & 17 \\
\hline More than one organ & 69 \\
\hline \multicolumn{2}{|l|}{ Surgical site } \\
\hline Thoracic surgery & 20 \\
\hline Abdomen & 59 \\
\hline Others & 7 \\
\hline
\end{tabular}

Table 1 (Continued)
Table 1 (Continued)

\begin{tabular}{|c|c|}
\hline Characteristics & $\mathrm{N}$ \\
\hline Time of surgical, median [range] & $180[60-500]$ \\
\hline ALB (g/L), median (range) & $28.0(15.8-49.0)$ \\
\hline CRE ( $\mu \mathrm{mol} / \mathrm{L})$, median (range) & $341.0(63.0-967.0)$ \\
\hline Urea (mmol/L), median (range) & $15.7(1.2-109.0)$ \\
\hline PCT (ng/mL), median (range) & $4.0(0.047-100.0)$ \\
\hline BNP (pmol/L), median (range) & $270.0(4.3-4,128.0)$ \\
\hline TnT (ng/mL), median (range) & $0.066(0.001-6.32)$ \\
\hline HGB (g/L), median (range) & $100.0(49.0-192.0)$ \\
\hline WBC $\left(10^{9} / \mathrm{L}\right)$, median (range) & $14.1(0.9-48.2)$ \\
\hline $\operatorname{PLT}\left(10^{6} / \mathrm{L}\right)$, median (range) & $170.0(5.0-655.0)$ \\
\hline
\end{tabular}

AKI, acute kidney injure; CRRT, continuous renal replacement therapy; ICU, intensive care unit; SAPS III, Simplified Acute Physiology Score III; SOFA, Sequential Organ Failure Assessment; ALB, albumin; CRE, creatinine; PCT, procalcitonin; BNP, brain natriuretic peptide; TnT, troponin T; HGB, hemoglobin; WBC, white blood cell; PLT, platelets.

internal jugular or subclavian vein catheter was used for vascular access. The blood flow was about $140 \mathrm{~mL} / \mathrm{min}$ with sodium citrate (initially at $8,000 \mathrm{mg} / \mathrm{h}$ ) for in vitro anticoagulation. Meanwhile $10 \%$ calcium gluconate was continuously pumped to body at the speed of $20 \mathrm{~mL} / \mathrm{h}$. The median cumulated overall CRRT duration was 50 (range: 14-290) hours.

\section{Statistical methods}

Continuous variables were expressed as median and interquartile range (IQR). Patients were followed up until the time of death or the point of 28-day after ICU admission. Twenty-eight-day survival probability was estimated by the Kaplan-Meier methods. Log-rank tests were used to compare 28-day survival probability between groups. Variables yielding $\mathrm{P}$ values $<0.05$ by univariate analysis and those considered clinically relevant were entered into the multivariate cox regression analysis. Results of multivariate analysis was summarized by estimating hazards ratios (HRs) and respective $95 \%$ confidence intervals (CIs). P value $<0.05$ was considered statistically significant. Statistical analyses were carried out with SPSS for Windows, version 19.0 (SPSS Inc., Chicago, IL, USA). 


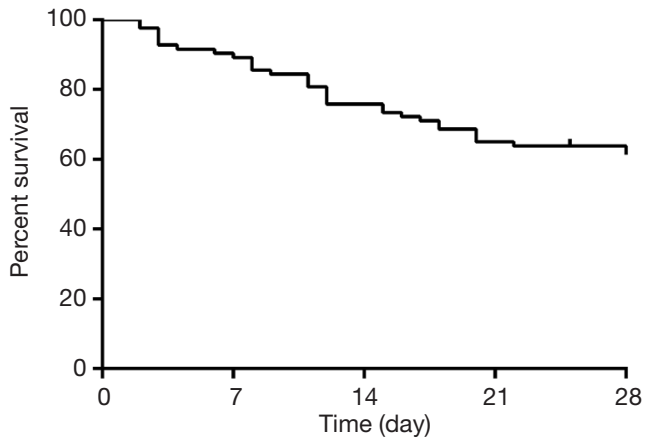

Figure 1 The survival rate of patients enrolled within 28 days in ICU. ICU, intensive care unit.

\section{Results}

\section{Clinical characteristics of the study population}

A total of 86 cancer patients with postoperative AKI-stage 3 treated with CRRT in the ICU were enrolled into our study. The median age was 61 (range: $27-82$ ) years. The ratio of male to female patients was 2.58:1. The median SOFA score was 6 [1-19] and the SAPS III was 65 [49-109]. The causes for ICU admissions were divided into three categories, $16(18.6 \%)$ patients presented with respiratory failure, 23 (26.7\%) patients with shock and 48 (55.8\%) patients with acute renal dysfunction. The percentage of digestive tract cancer (esophagus, stomach, colon, hepatobiliary, pancreas) and lung cancer were $68.6 \%$ and $11.6 \%$, respectively. The remaining $19.8 \%$ of enrolled patients were other types of cancer (brain, head and neck, gynecology). Sixty-seven (77.9\%) patients were presented with localized tumors and underwent a completely resection, whereas 19 (22.1\%) patients were accompanied with distant metastasis and accepted palliative resection. Twenty patients were under the thoracic surgery, 59 patients were operated abdomen surgery. The remaining seven patients underwent head or neck or gynecology surgery. The median operation duration was 180 [50-100] minutes. Of 86 patients, 19 individuals were administrated with regimens of doxorubicin and ifosfamide, with or without dacarbazine. Three patients underwent 40-76 Gy of radiotherapy to primary and/or recurrent lesions within the last 90 days before operation. The number of comorbidities with diabetes, hypertensions, coronary heart diseases was 16,35 , and 12 , respectively. At the start of CRRT, 49 (57.0\%) patients required vasopressors including 40 sepsis shock patients and nine ischemia shock patients. Fifty-three (61.6\%) patients was given MV because of respiratory failure. The MV duration was 3 [1-10] days overall. All patients enrolled received rehabilitation and general medicine services.

\section{Twenty-eight-day survive for critically ill cancer patients undergoing CRRT with postoperative AKI}

Thirty-five of 86 patients died eventually after ICU admission within 28 days. The 28 -day survival rate was $57.1 \% \pm 5.8 \%$ (Figure 1). Among the 35 deaths, multiple organ failure was in 15 (42.9\%), sepsis shock was in 10 (28.6\%), respiratory failure was in $9(25.7 \%)$, and cardiac arrest was in $6(17.1 \%)$. Renal function was completely reestablished in $34(66.7 \%)$ and partially reestablished in 12 (23.5\%), and only 4 (9.8\%) of survivors required chronic dialysis.

\section{Univariate analyses of prognostic factors affecting 28-day survive}

Table 2 reported the results of the univariate analysis. Twenty-eight-day survive was associated with surgical site $(\mathrm{P}=0.036)$, types of cancer $(\mathrm{P}=0012)$, serum album $(\mathrm{P}=0.017)$, the presence of respiratory failure $(\mathrm{P}=0.003)$ /shock $(\mathrm{P}<0.001)$ at the time of the initiation of CRRT, SAPS III $(\mathrm{P}<0.001)$, SOFA score $(\mathrm{P}=0.021)$, the number of organ failure $(\mathrm{P}=0.044)$, causes of ICU admission $(\mathrm{P}=0.002)$, the concentration of serum BNP $(\mathrm{P}<0.001)$, the concentration of serum PCT $(\mathrm{P}<0.001)$. The 28 -day survival rate showed no significance between patients with locoregional tumor and metastatic tumor (Figure 2, $\mathrm{P}=0.208$ ).

\section{Multivariate analysis of prognostic factors of 28-day survive (Table 3)}

In multivariate cox regression analysis: SAPS III score $\geq 65$ [HR: 3.451 (1.272-9.365), $\mathrm{P}=0.015$ ] and the presence of shock at the start of CRRT [HR: 10.262 (2.21047.660), $\mathrm{P}=0.003$ ] at the time of the initiation of CRRT independently affected 28 -day survive. The 28 -day survive rate of patients with SAPS III score $<65$ and $\geq 65$ were $81.3 \%(67.1-89.8 \%)$ and $27.6 \%(13.3-44.0 \%)$, respectively (Figure 3). For the whole group, SAPS III score $\geq 65$ with a 2.451-fold increased risk of 28-day morality than the patients with SAPS III score $<65(\mathrm{P}<0.001)$. The 28 -day survive rate of the patients with the presence of shock at the start of CRRT was $31.4 \%(17.9-45.8 \%)$, which was obviously lower than that of the patients without the presence of shock (Figure 4, $\mathrm{P}<0.001)$. 
Table 2 Prognostic factors for hospital mortality-univariate analysis

\begin{tabular}{|c|c|c|c|}
\hline Factors & $\mathrm{N}$ & Survive $(95 \% \mathrm{Cl}), \%$ & $\mathrm{P}$ \\
\hline$\leq 60$ & 38 & $54.6(35.6-70.2)$ & \\
\hline$>60$ & 48 & $59.6(44.2-72.0)$ & \\
\hline Gender & & & 0.708 \\
\hline Male & 49 & $58.3(36.5-75.0)$ & \\
\hline Cancer status & & & 0.076 \\
\hline Locoregional & 67 & $61.3(47.2-72.7)$ & \\
\hline Metastatic & 19 & $42.1(20.4-62.5)$ & \\
\hline ALB (g/L) & & & 0.017 \\
\hline No & 33 & $78.8(60.6-89.3)$ & \\
\hline Yes & 53 & $43.7(28.7-57.8)$ & \\
\hline Shock & & & $<0.001$ \\
\hline No & 37 & 91.9 (76.9-97.3) & \\
\hline Yes & 49 & $31.4(17.9-45.8)$ & \\
\hline SAPS III & & & $<0.001$ \\
\hline$<65$ & 48 & $81.3(67.1-89.8)$ & \\
\hline$\geq 65$ & 38 & $27.6(13.3-44.0)$ & \\
\hline More than one organ & 69 & $50.8(37.4-62.8)$ & \\
\hline CRE (mmol/L) & & & 0.152 \\
\hline$<350$ & 46 & 48.5 (31.8-63.2) & \\
\hline$\geq 350$ & 40 & $67.5(50.7-79.7)$ & \\
\hline Adjuvant treatment & & & 0.949 \\
\hline No & 64 & $56.4(42.0-68.5)$ & \\
\hline Yes & 22 & $59.1(36.1-76.2)$ & \\
\hline Hypertension & & & 0.781 \\
\hline No & 51 & $53.2(36.9-67.0)$ & \\
\hline Yes & 35 & $62.9(44.8-76.5)$ & \\
\hline Diabetes & & & 0.894 \\
\hline No & 70 & $55.8(42.3-67.4)$ & \\
\hline Yes & 16 & $62.5(34.9-81.1)$ & \\
\hline
\end{tabular}

Table 2 (Continued) 
Table 2 (Continued)

\begin{tabular}{|c|c|c|c|}
\hline Factors & $\mathrm{N}$ & Survive (95\% Cl), \% & $\mathrm{P}$ \\
\hline Coronary heart disease & & & 0.102 \\
\hline No & 74 & $59.6(46.3-70.6)$ & \\
\hline BNP (pmol/L) & & & $<0.001$ \\
\hline$<270$ & 44 & $75.0(57.4-86.2)$ & \\
\hline $\mathrm{TnT}(\mathrm{ng} / \mathrm{mL})$ & & & 0.156 \\
\hline$<0.1$ & 52 & $59.8(43.4-72.9)$ & \\
\hline$\geq 0.1$ & 34 & $52.9(35.1-68.0)$ & \\
\hline PCT (ng/mL) & & & $<0.001$ \\
\hline$<16$ & 45 & $55.6(40.0-68.6)$ & \\
\hline$\geq 16$ & 41 & $58.9(39.8-73.7)$ & \\
\hline WBC $\left(10^{9} / L\right)$ & & & 0.905 \\
\hline$<15$ & 45 & $53.6(36.1-68.4)$ & \\
\hline$\geq 15$ & 41 & $61.0(44.4-74.0)$ & \\
\hline HGB (g/L) & & & 0.674 \\
\hline$<100$ & 44 & 56.8 (41.0-69.9) & \\
\hline$\geq 100$ & 42 & 57.5 (38.8-72.3) & \\
\hline$>180$ & 33 & $68.8(49.7-81.8)$ & \\
\hline Types of cancer & & & 0.012 \\
\hline Lung & 12 & $40.0(12.3-67.0)$ & \\
\hline Digestive system & 59 & $66.1(51.5-77.2)$ & \\
\hline Others & 15 & $36.6(13.2-60.8)$ & \\
\hline Surgical site & & & 0.036 \\
\hline Thoracic & 17 & $50.0(24.5-71.1)$ & \\
\hline Abdomen & 57 & $63.3(47.7-75.5)$ & \\
\hline Others & 12 & $38.5(14.1-62.8)$ & \\
\hline Causes of ICU admission & & & 0.002 \\
\hline Respiratory failure & 16 & $32.8(10.3-57.9)$ & \\
\hline Shock & 23 & $39.9(18.5-60.5)$ & \\
\hline Acute renal dysfunction & 47 & 74.5 (59.4-84.6) & \\
\hline
\end{tabular}
ALB, albumin; SAPS III, Simplified Acute Physiology Score III; SOFA, Sequential Organ Failure Assessment; CRE, creatinine; BNP, brain natriuretic peptide; TnT, troponin T; PCT, procalcitonin; WBC, white blood cell; HGB, hemoglobin; PLT, platelets; ICU, intensive care unit. 


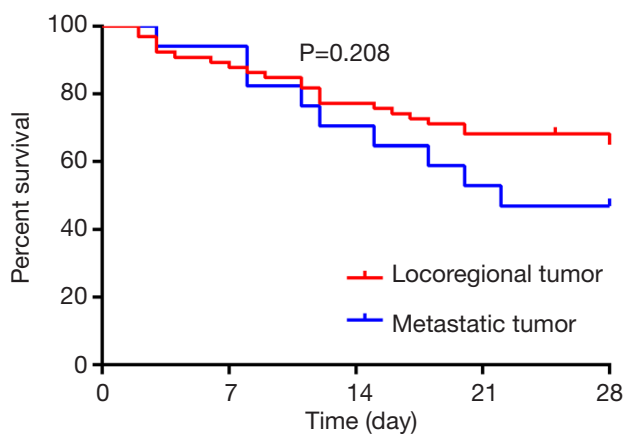

Figure 2 The survival rate of patients with locoregional tumor and metastatic tumor showed no significance within 28 days $(\mathrm{P}=0.208)$

\section{Discussion}

AKI has been reported to occur in $5-7 \%$ of hospitalized patients, but it accounts for up to $20 \%$ of admissions in ICU (7). It is a common postoperative complication (15) defined by a sudden decline in the kidney function, ranging from subclinical AKI to AKI patients receiving RRT $(16,17)$. Despite improvements in the general management of ICU patients with cancer, AKI worsens the prognosis. In patients with cancer requiring CRRT, hospital mortality rates are reported between $51 \%$ and $90 \%(18,19)$. The difference of the short-term survive may be partly attributed to the difference between solid tumors and hematological tumors. In our study, the 28 -day survival rate was $57.1 \% \pm 5.8 \%$, which is higher than previous research.

RRT is an effective therapy for AKI-stage three patients to date. The KDIGO criteria advocates to start RRT when water overload becomes life-threatening or sever imbalances (such as hyperkalemia $>6.5 \mathrm{mmol} / \mathrm{L}$, severe metabolic acidosis and uremia) occur (4). Historically, it remains controversial to start CRRT for AKI in critically ill patients with cancer because of the poor outcome and high costs $(6,18,20-23)$. The rate of AKI in patients admitted to a comprehensive cancer center was higher than the rate in most noncancer settings (24). In most previous study performed in cancer patients admitted for medical complications in the ICU, the cancer characteristics were not predictive factors for hospital mortality (25). Benoit conducted a prospective cohort study in 14 ICUs from three tertiary care hospitals and founded that in general ICUs, the presence of cancer was not independently associated with hospital mortality (26). In our study, the types of cancer affected 28-day survive by univariate analysis $(\mathrm{P}=0.012)$, however none of the cancer status $(\mathrm{P}=0.076)$, neoadjuvant therapy associated with cancer $(\mathrm{P}=0.949)$, the types of cancer ( $\mathrm{P}>0.05$ for both) was a prognostic factor of 28 -day survive by multivariate analysis. As previously reported, short-term survive was linked to acute physiological changes induced by the complications leading to ICU admission while cancer characteristics influenced significantly survival after hospital discharge $(27,28)$. When evaluating prognosis and the appropriateness of CRRT in these patients, cancer characteristics were not important variables to take into consideration.

Shock is often routinely considered as a poor prognostic factor. In our study, 49 patients developed shock including 40 sepsis shock and nine ischemia shock at the start of CRRT. The presence of shock at the time of the initiation of CRRT [HR: 10.262 (2.210-47.660), $\mathrm{P}=0.003$ ] independently affecting the 28-day-survive. Our finding was consistent with previous studies. Maccariello et al. (29) conducted an analysis of 150 patients and found patients with AKI in need of vasopressors to be associated with higher hospital mortality [odds ratio (OR): 3.58 (1.0811.80)]. Another retrospective study conducted by Kim et al. (3), which included 4,718 patients with gastric cancer who underwent partial or total gastrectomy for gastric cancer between June 2002 and December 2011, reported that vasopressor usage was associated with a high 3-month mortality in patients with postoperative AKI.

A predictive model for short-term survive in AKI patients requiring CRRT may help clinicians' therapeutic decisionmaking. Sequential assessment of organ dysfunction during the first few days of ICU admission is a good indicator of prognosis (13). A single-center study conducted in a cancerspecialized ICU in Brazil reported that hospital mortality was $86.8 \%$ for AKI patients (KDIGO stage 3). SOFA and SAPS III were independent factors for mortality in this population by logistic regression analysis (30). In our study, we accepted the score of SOFA and SAPS III within the first 24 hours of admission to assess the criticality of patients. The SAPS III calculated within the first 24 hours of admission was significantly $(\mathrm{P}<0.001)$ related to 28 -day survive when the SAPS III was higher than 65 .

PCT is a polypeptide composed of 116 amino acids synthesized by parafollicular cells of the thyroid and the neuroendocrine cells of the lung and the intestine. It is a promising sepsis marker (31) which is suggestive of sepsis (32). Many previous studies have found that PCT levels in survivors were lower than that in nonsurvivors $(33,34)$. But PCT is not an early biomarker for prognosis in septic patients because that renal function 
Table 3 Prognostic factors for hospital mortality-multivariate analysis

\begin{tabular}{|c|c|c|c|c|c|c|}
\hline Factors & $\mathrm{B}$ & SE & Wald & $\mathrm{HR}$ & $95 \% \mathrm{Cl}$ & $\mathrm{P}$ \\
\hline \multicolumn{7}{|l|}{ Surgical site } \\
\hline \multicolumn{7}{|l|}{ Abdomen } \\
\hline Thoracic & -0.909 & 0.767 & 1.404 & 0.403 & $0.090-1.812$ & 0.236 \\
\hline Others & 1.892 & 0.915 & 2.474 & 6.635 & $1.103-39.903$ & 0.039 \\
\hline \multicolumn{7}{|l|}{ Types of cancer } \\
\hline Lung & 1.7801 & 0.984 & 3.270 & 5.927 & $0.861-40.783$ & 0.071 \\
\hline Others & -0.331 & 0.806 & 0.169 & 0.718 & $0.148-3.489$ & 0.681 \\
\hline \multicolumn{7}{|l|}{ ALB (g/L) } \\
\hline \multicolumn{7}{|l|}{ No } \\
\hline Yes & 1.036 & 0.577 & 3.225 & 2.817 & $0.910-8.721$ & 0.073 \\
\hline \multicolumn{7}{|l|}{ Shock } \\
\hline \multicolumn{7}{|l|}{ No } \\
\hline Yes & 2.328 & 0.783 & 8.832 & 10.262 & $2.210-47.660$ & 0.003 \\
\hline \multicolumn{7}{|l|}{ SAPS III } \\
\hline \multicolumn{7}{|l|}{$<65$} \\
\hline$\geq 65$ & 1.239 & 0.509 & 5.914 & 3.451 & $1.272-9.365$ & 0.015 \\
\hline$\geq 1$ & 0.055 & 0.840 & 0.004 & 1.057 & $0.204-5.482$ & 0.948 \\
\hline \multicolumn{7}{|l|}{ BNP (pmol/L) } \\
\hline \multicolumn{7}{|l|}{$<270$} \\
\hline$\geq 270$ & 0.726 & 0.447 & 2.631 & 2.066 & $0.860-4.966$ & 0.105 \\
\hline \multicolumn{7}{|l|}{ PCT (ng/mL) } \\
\hline \multicolumn{7}{|l|}{$<4$} \\
\hline$\geq 4$ & 0.553 & 0.476 & 1.352 & 1.739 & $0.684-4.422$ & 0.245 \\
\hline \multicolumn{7}{|c|}{ Causes of ICU admission } \\
\hline \multicolumn{7}{|l|}{ AKI } \\
\hline Respiratory failure & 0.217 & 0.623 & 0.121 & 1.242 & $0.366-4.215$ & 0.728 \\
\hline Shock & -0.498 & 0.556 & 0.804 & 0.607 & $0.204-1.805$ & 0.607 \\
\hline
\end{tabular}

HR, hazard ratio; CI, confidence interval; ALB, albumin; SAPS III, Simplified Acute Physiology Score III; SOFA, Sequential Organ Failure Assessment; BNP, brain natriuretic peptide; PCT, procalcitonin; ICU, intensive care unit. 


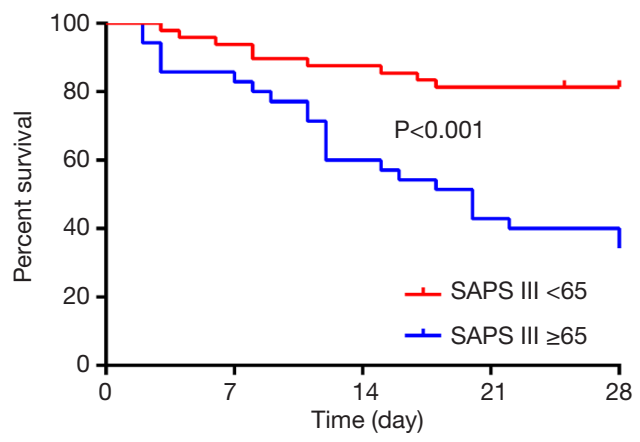

Figure 3 The patients with SAPS III $\geq 65$ with a poor prognosis compared with SAPS III <65. SAPS III, Simplified Acute Physiology Score III.

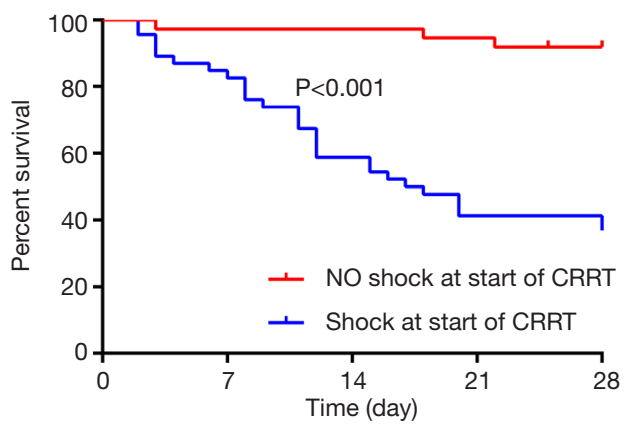

Figure 4 The survival rate of patients with or without shock at start of CRRT showed significance within 28 days $(\mathrm{P}<0.001)$. CRRT, continuous renal replacement therapy.

is an important determinant of PCT levels and thus different thresholds should be applied according to the renal function impairment (35). TnT is higher than normal in a large percentage of patients with acute heart failure, indicating the presence of myocardial damage and is a good independent predictor of 1-year mortality (36). BNP is known to relate with the dysfunction of the cardiovascular system (37). Previous studies have also reported the use of BNP for the assessment of volume status in critically ill patients. Elevated BNP concentrations at admission in the setting of acute coronary syndrome are associated with poor prognosis (38). There is a wealth of data on their significance as poor prognostic factors. In the present study, the concentration of PCT $(\mathrm{P}<0.001)$ and BNP $(\mathrm{P}<0.001)$ affected the 28-day survive by univariate analysis. However, none of the three was independent prognostic factors for 28-day survive.
Our study has some shortcomings. Firstly, it is a singlecenter, retrospective study. The type of tumor has not been further subdivided into organs and even histopathology. Secondly, when studying the impact of tumor properties on prognosis, due to the limitation of oncology hospitals, non-tumor patients could not be selected for comparison. Thirdly, due to the low incidence and long case span, previous support measures were limited, which may affect the prognosis.

\section{Conclusions}

In conclusion, for cancer patients with postoperative AKIstage 3 in ICU, 28-day survive rate is low and some factors may indicate poor prognosis, which was in consistent with general hospital. For these patients with advanced cancer, we should not treat them differently from patients with locoregional cancer because of undifferentiated shortterm prognosis. These patients can also benefit from ICU care and advanced organ support. The presence of cancer characteristics by itself is not a reason to withhold CRRT in ICU patients with postoperative AKI.

\section{Acknowledgments}

Funding: None.

\section{Footnote}

Reporting Checklist: The authors have completed the STROBE reporting checklist. Available at http://dx. doi. org/10. 21037/tcr-20-1324

Data Sharing Statement: Available at http://dx. doi. org/10. 21037/tcr-20-1324

Conflicts of Interest: All authors have completed the ICMJE uniform disclosure form (available at http://dx. doi. org/10.21037/tcr-20-1324). The authors have no conflicts of interest to declare.

Ethical Statement: The authors are accountable for all aspects of the work in ensuring that questions related to the accuracy or integrity of any part of the work are appropriately investigated and resolved. The study was conducted in accordance with the Declaration of Helsinki (as revised in 2013). The ethics committees in our hospital approved the study (No. NCC2020C-162) and the need 
for informed consent was waived because there was no interference with decisions related to patient's care.

Open Access Statement: This is an Open Access article distributed in accordance with the Creative Commons Attribution-NonCommercial-NoDerivs 4.0 International License (CC BY-NC-ND 4.0), which permits the noncommercial replication and distribution of the article with the strict proviso that no changes or edits are made and the original work is properly cited (including links to both the formal publication through the relevant DOI and the license). See: https://creativecommons.org/licenses/by-nc-nd/4.0/.

\section{References}

1. Soares M, Salluh JI, Carvalho MS, et al. Prognosis of critically ill patients with cancer and acute renal dysfunction. J Clin Oncol 2006;24:4003-10.

2. Darmon M, Thiery G, Ciroldi M, et al. Should dialysis be offered to cancer patients with acute kidney injury? Intensive Care Med 2007;33:765-72.

3. Kim CS, Oak CY, Kim HY, et al. Incidence, predictive factors, and clinical outcomes of acute kidney injury after gastric surgery for gastric cancer. PLoS One 2013;8:e82289.

4. Meersch M, Schmidt C, Zarbock A. Perioperative acute kidney injury: an under-recognized problem. Anesth Analg 2017;125:1223-32.

5. Menashe PI, Ross SA, Gottlieb JE. Acquired renal insufficiency in critically ill patients. Crit Care Med 1988;16:1106-9.

6. Brivet FG, Kleinknecht DJ, Loirat P, et al. Acute renal failure in intensive care units--causes, outcome, and prognostic factors of hospital mortality; a prospective, multicenter study. French Study Group on Acute Renal Failure. Crit Care Med 1996;24:192-8.

7. Thakar CV, Christianson A, Freyberg R, et al. Incidence and outcomes of acute kidney injury in intensive care units: a Veterans Administration study. Crit Care Med 2009;37:2552-8.

8. Canaud B. Postoperative acute renal failure: definition, diagnostic and prognostic criteria. Ann Fr Anesth Reanim 2005;24:125-33.

9. Berghmans T, Meert AP, Markiewicz E, et al. Continuous venovenous haemofiltration in cancer patients with renal failure: a single-centre experience. Support Care Cancer 2004;12:306-11.

10. Fischler R, Meert AP, Sculier JP, et al. Continuous renal replacement therapy for acute renal failure in patients with cancer: a well-tolerated adjunct treatment. Front Med (Lausanne) 2016;3:33.

11. Han AR, Kim DY, Suh DS, et al. Postoperative acute renal failure in patients with gynecologic malignancies: analysis of 10 cases and review of the literature. J Gynecol Oncol 2009;20:55-9.

12. Palevsky PM, Liu KD, Brophy PD, et al. KDOQI US commentary on the 2012 KDIGO clinical practice guideline for acute kidney injury. Am J Kidney Dis 2013;61:649-72.

13. Ferreira FL, Bota DP, Bross A, et al. Serial evaluation of the SOFA score to predict outcome in critically ill patients. JAMA 2001;286:1754-8.

14. Moreno RP, Metnitz PG, Almeida E, et al. SAPS 3--From evaluation of the patient to evaluation of the intensive care unit. Part 2: Development of a prognostic model for hospital mortality at ICU admission. Intensive Care Med 2005;31:1345-55.

15. Gameiro J, Fonseca JA, Neves M, et al. Acute kidney injury in major abdominal surgery: incidence, risk factors, pathogenesis and outcomes. Ann Intensive Care 2018;8:22.

16. Bellomo R, Ronco C, Kellum JA, et al. Acute renal failure - definition, outcome measures, animal models, fluid therapy and information technology needs: the Second International Consensus Conference of the Acute Dialysis Quality Initiative (ADQI) Group. Crit Care 2004;8:R204-12.

17. Chertow GM, Burdick E, Honour M, et al. Acute kidney injury, mortality, length of stay, and costs in hospitalized patients. J Am Soc Nephrol 2005;16:3365-70.

18. Negi S, Koreeda D, Kobayashi S, et al. Acute kidney injury: Epidemiology, outcomes, complications, and therapeutic strategies. Semin Dial 2018;31:519-27.

19. Létourneau I, Dorval M, Bélanger R, et al. Acute renal failure in bone marrow transplant patients admitted to the intensive care unit. Nephron 2002;90:408-12.

20. Masoomi H, Carmichael JC, Dolich M, et al. Predictive factors of acute renal failure in colon and rectal surgery. Am Surg 2012;78:1019-23.

21. Gumbert SD, Kork F, Jackson ML, et al. Perioperative acute kidney injury. Anesthesiology 2020;132:180-204.

22. Audisio RA. Risk factors for morbidity and mortality after colectomy for colon cancer. Tech Coloproctol 2001;5:177-9.

23. Uchino S, Kellum JA, Bellomo R, et al. Acute renal failure in critically ill patients: a multinational, multicenter study. JAMA 2005;294:813-8. 
24. Salahudeen AK, Doshi SM, Pawar T, et al. Incidence rate, clinical correlates, and outcomes of AKI in patients admitted to a comprehensive cancer center. Clin J Am Soc Nephrol 2013;8:347-54.

25. Sculier JP, Paesmans M, Markiewicz E, et al. Scoring systems in cancer patients admitted for an acute complication in a medical intensive care unit. Crit Care Med 2000;28:2786-92.

26. Benoit DD, Hoste EA, Depuydt PO, et al. Outcome in critically ill medical patients treated with renal replacement therapy for acute renal failure: comparison between patients with and those without haematological malignancies. Nephrol Dial Transplant 2005;20:552-8.

27. Soares M, Caruso P, Silva E, et al. Characteristics and outcomes of patients with cancer requiring admission to intensive care units: a prospective multicenter study. Crit Care Med 2010;38:9-15.

28. Lecuyer L, Chevret S, Thiery G, et al. The ICU trial: a new admission policy for cancer patients requiring mechanical ventilation. Crit Care Med 2007;35:808-14.

29. Maccariello E, Soares M, Valente C, et al. RIFLE classification in patients with acute kidney injury in need of renal replacement therapy. Intensive Care Med 2007;33:597-605.

30. Libório AB, Abreu KL, Silva GB Jr, et al. Predicting hospital mortality in critically ill cancer patients according to acute kidney injury severity. Oncology 2011;80:160-6.

31. Pierrakos C, Vincent JL. Sepsis biomarkers: a review. Crit Care 2010;14:R15.

32. Sudhir U, Venkatachalaiah RK, Kumar TA, et al. Significance of serum procalcitonin in sepsis. Indian J Crit
Care Med 2011;15:1-5.

33. Zhao Y, Li C, Jia Y. Evaluation of the Mortality in Emergency Department Sepsis score combined with procalcitonin in septic patients. Am J Emerg Med 2013;31:1086-91.

34. Magrini L, Travaglino F, Marino R, et al. Procalcitonin variations after Emergency Department admission are highly predictive of hospital mortality in patients with acute infectious diseases. Eur Rev Med Pharmacol Sci 2013;17 Suppl 1:133-42.

35. Amour J, Birenbaum A, Langeron O, et al. Influence of renal dysfunction on the accuracy of procalcitonin for the diagnosis of postoperative infection after vascular surgery. Crit Care Med 2008;36:1147-54.

36. Guisado Espartero ME, Salamanca-Bautista P, Aramburu-Bodas O, et al. Troponin T in acute heart failure: clinical implications and prognosis in the Spanish National Registry on Heart Failure. Eur J Intern Med 2014;25:739-44.

37. Yancy CW, Jessup M, Bozkurt B, et al. 2017 ACC/ AHA/HFSA Focused Update of the 2013 ACCF/AHA Guideline for the Management of Heart Failure: A Report of the American College of Cardiology/American Heart Association Task Force on Clinical Practice Guidelines and the Heart Failure Society of America. J Card Fail 2017;23:628-51.

38. Radwan H, Selem A, Ghazal K. Value of N-terminal pro brain natriuretic peptide in predicting prognosis and severity of coronary artery disease in acute coronary syndrome. J Saudi Heart Assoc 2014;26:192-8.
Cite this article as: Yuan ZN, Wang HJ, Qu SN, Huang CL, Wang H, Zhang H, Yang QH, Xing XZ. The 28-day survive for critically ill cancer patients undergoing continuous renal replacement with postoperative acute kidney injure: a retrospective study of 86 cases. Transl Cancer Res 2020;9(10):62216231. doi: $10.21037 /$ tcr-20-1324 